\title{
A ATUAÇÃO DO FARMACÊUTICO EM ATENDIMENTO COM PACIENTE AUTISTA - UM RELATO DE EXPERIÊNCIA
}

\section{Daiara Machado da Silva'; Karla Luana Ávila de Borba ${ }^{2}$; Ligia Zorzi Gomes ${ }^{3}$; Mariana Kristosch dos Santos ${ }^{4}$; Verônica Bidigaray Sanches ${ }^{5}$; Minéia Weber Blattes $^{6}$}

\section{RESUMO}

Atualmente, as alterações na saúde mental da sociedade estão cada vez mais presentes. Com isso, as residentes atuam para dar suporte aos indivíduos e familiares. O presente artigo é um relato de experiência construído a partir das vivências da profissional farmacêutica em um Centro de Atenção Psicossocial Infantojuvenil (CAPSi), um dos campos de atuação da Residência Multiprofissional em Saúde Mental da Universidade Franciscana (UFN). Trata-se de um estudo qualitativo que objetiva discutir a inserção e atuação das residentes, principalmente de uma farmacêutica em atendimentos com paciente autista. Concluímos que essa atuação é benéfica, trazendo ótimos resultados aos usuários e contribuições significativas para o serviço.

Palavras-chave: Farmácia; Residência Multiprofissional; Saúde mental.

Eixo Temático: Atenção Integral e Promoção à Saúde.

\section{INTRODUÇÃO}

A residência em Área Profissional da Saúde foi instituída através da lei no 11.129 , de 30 de junho de 2005, em que é definida como modalidade de pósgraduação lato sensu, sendo voltada para a educação em serviço e destinada às categorias profissionais que integram a área da saúde. Constituindo-se um programa de cooperação intersetorial com o objetivo de favorecer a inserção qualificada dos jovens profissionais de saúde no mercado de trabalho (BRASIL, 2005).

\footnotetext{
${ }^{1}$ Farmacêutica - Residente em Saúde Mental - UFN daiara.machado@ufn.edu.br

2 Psicóloga - Residente em Saúde Mental - UFN karla.avila@ufn.edu.br

${ }^{3}$ Terapeuta Ocupacional - Residente em Saúde Mental - UFN ligia.zorzi@ufn.edu.br

${ }^{4}$ Psicóloga - Preceptora do campo do CAPSi - psicomarianasm@gmail.com

${ }^{5}$ Assistente Social - Residente em Saúde Mental - UFN veronica.sanches@ufn.edu.br

${ }^{6}$ Orientadora - Tutora da Residência Multiprofissional - UFN mweber@ufn.edu.br
} 
Os transtornos mentais têm grande importância na sociedade e estão em constante crescimento. Atualmente quase 1 bilhão de pessoas vivem com transtorno mental, 3 milhões de pessoas morrem todos os anos devido ao uso nocivo do álcool e uma pessoa morre a cada 40 segundos por suicídio e relativamente poucas pessoas em todo o mundo têm acesso a serviços de saúde mental de qualidade (OMS, 2020).

Frente a isso, a residência multiprofissional está inserida também na saúde mental, dando suporte e apoio aos indivíduos e familiares, tendo o Centro de Atenção Psicossocial Infantojuvenil (CAPSi) como um campo de atuação. O CAPSi é um serviço de atenção psicossocial para atendimentos a crianças e adolescentes, prestando diversas atividades, entre elas os atendimentos individuais e em grupos, visitas domiciliares e atividades comunitárias (BRASIL, 2002).

Visto que todo profissional da área da saúde pode atuar como profissional da saúde mental, a autora farmacêutica em conjunto com a terapeuta ocupacional atendem uma criança com transtorno do espectro do autismo (TEA). O autismo é uma condição de origem multifatorial em que se expressa com diferentes níveis de intensidade e comorbidades associadas. Os indivíduos afetados apresentam déficits na linguagem, na comunicação interpessoal e restringem-se a comportamentos repetitivos, que prejudicam sua interação com a sociedade (SUNAKOZAWA; MATHIAS; VIDOTTI, 2020).

\section{METODOLOGIA}

Este trabalho constitui um relato de experiência, acompanhado pela autora farmacêutica e residente multiprofissional na área de saúde mental da Universidade Franciscana em um dos campos de atuação, o CAPSi. Trata-se de um estudo qualitativo, por métodos observacionais no qual busca apresentar uma reflexão em âmbito profissional e de interesse da comunidade científica, estabelecendo conexões entre a teoria e a prática. A atuação profissional a qual resultou nesse trabalho se desenvolveu no primeiro semestre de 2021, durante o primeiro ano de ingresso na residência. 


\section{RESULTADOS E DISCUSSÕES}

Com a implantação do Sistema Único de Saúde (SUS) em 1990, deu início à organização de um sistema de caráter público, com princípios e diretrizes comuns em todo o território nacional. E foram criadas Comissões Permanentes de integração entre os serviços de saúde e as instituições de ensino profissional e superior, com finalidade de propor prioridades, métodos e estratégias para a formação e educação continuada dos recursos humanos do SUS, assim como em relação à pesquisa e à cooperação técnica entre essas instituições (BRASIL, 1990). Assim, a residência contribui para uma aprendizagem na prática, através das interações com os demais residentes e com a equipe do serviço, em que possibilita uma troca de informações e conhecimentos.

O CAPSi relatado não possui área de dispensação de medicamentos e nem uma farmacêutica inserida na equipe. A inserção das residentes das áreas de farmácia, psicologia, terapia ocupacional e assistência social se deu através de pactuação entre o campo de atuação e a instituição, visto que é um serviço que obtem uma grande demanda encaminhada por outras unidades de saúde. Com todas essas formações juntas tem um arsenal de ideias e uma oportunidade de novos conhecimentos acerca de outras áreas e isso faz com que profissões diferentes se auxiliem e se complementem em prol do usuário.

As Residências Multiprofissionais em Saúde promovem interação entre gestores, profissionais dos serviços, profissionais residentes, docentes e usuários, e também aproximam os campos da saúde e da educação. Então, o Programa de Residência Multiprofissional em Saúde surge como uma estratégia para a reorganizar os serviços públicos embasado nos princípios do SUS (SILVA; ARAUJO, 2019).

A residência em saúde mental coloca o farmacêutico frente a atuação diretamente com o paciente, auxiliando sobre uso, doses e posologias dos medicamentos. É prestado também o atendimento farmacêutico, que é o ato em que o profissional, fundamentado em seu exercício, interage e responde às demandas dos usuários, buscando a resolução de problemas de saúde, que envolvam ou não o uso de medicamentos. Este processo pode compreender escuta ativa, identificação 
de necessidades, análise da situação, tomada de decisões, definição de condutas, documentação e avaliação (CONSENSO BRASILEIRO DE ATENÇÃO FARMACÊUTICA, 2002).

No CAPSi é realizado suporte aos pacientes, realizando tanto os tratamentos clínicos, quanto a promoção de intervenções que proporcionam a reinserção destes pacientes no contexto social e familiar. Com isto, propõem que se realizem ações de integralidade a atenção e a humanização a assistência promovendo condições para que existam relacionamentos sadios entre a equipe multiprofissional e o paciente com transtorno mental, de modo a realizar um projeto terapêutico singular (PTS) de acordo com as necessidades de cada paciente e da sua situação familiar (CAMARGO, 2016). Assim, o farmacêutico auxilia nestes processos e se vincula com o paciente em seu atendimento, prestando todo apoio e estratégias para prestar sua assistência.

O paciente acompanhado pela autora tem autismo e utiliza os medicamentos escitalopram, ácido valpróico e risperidona, prescritos por uma psiquiatra que acompaha o caso. A ampla farmacoterapia, na maioria das vezes, é necessária e imposta como tratamento inicial para o paciente (OLIVEIRA et al., 2015). O acompanhamento farmacoterapêutico se faz essencial pois as crianças e os responsáveis que administram os medicamentos, podem interferir na adesão terapêutica do usuário (NIKOLOV; JONKER; SCAHILL, 2006).

Contudo, o profissional mais apto à realização e condução de um seguimento farmacoterapêutico é o farmacêutico. Este profissional conhece sobre medicamentos e suas interações, e ajuda a evitar problemas relacionados ao uso, além de sugerir uma melhor conduta no manejo terapêutico (SCARCELA; MUNIZ; CIRQUEIRA, 2011). Com isso, a farmacêutica observa o comportamento do paciente nos atendimentos que são realizados semanalmente, sendo perceptíveis as melhoras no desenvolvimento e no comportamento em cada atendimento.

Durante o atendimento são expostas atividades de forma lúdica que chame a atenção da criança e dessa forma, ela realize o trabalho proposto. Também tem momentos em que a criança é colocada para desenvolver a sua criatividade e sugerir brincadeiras que atraiam a sua atenção. 
O componente de imaginação de uma brincadeira infantil tem natureza e origem social, isso porque a criança reelabora as formas humanas de agir com objetos e de interagir com outros a partir de suas condições concretas de vida, mas criando novas realidades. Com isso, ao brincar, ela se envolve com regras de comportamento e valores sociais, com os quais muitas vezes não conseguiria realizar fora dessa atividade (MARTINS; GÓES, 2013).

Os procedimentos educacionais e terapêuticos de crianças com TEA visam auxiliar o desenvolvimento do aspecto social e por isso devem envolver duplas ou pequenos grupos, onde a atividade terá como função diversificar o repertório comunicativo da criança com autismo (FERNANDES, 2004). Os atendimentos realizados em duplas, por exemplo, facilitam o processo de preparação e a possibilidade de conversar e estudar sobre o caso e sempre buscar novas metodologias a serem usadas.

\section{CONCLUSÃO}

Os transtornos mentais contribuem significativamente para a carga global de doenças da população e estão associados a deficiências e também as doenças desenvolvidas pela carga de estresse, preocupação e ansiedade, além de interferir em custos para a saúde, diminuição da produtividade e da qualidade de vida. $\mathrm{O}$ CAPSi atua diariamente com esses usuários e o tratamento muitas vezes é medicamentoso e com riscos de interações, o que se faz fundamental a atuação do farmacêutico frente a esse serviço.

Poucos CAPS têm a atuação de um farmacêutico como parte da equipe, o que deveria estar sempre presente, visto que já se tem benefícios dessa atuação com a equipe e usuários no fortalecimento dos resultados dos tratamentos.

Para uma farmacêutica realizar atendimentos com crianças é algo novo e diferenciado, em que o habitual é o contato com adultos. Nesta vivência, percebeuse o quanto é satisfatório e encantador poder desempenhar esse papel que oferece um grande aprendizado e desenvolvimento tanto profissional quanto pessoal. 


\section{QUFN}

\section{REFERÊNCIAS}

BRASIL. Lei 8.080, de 19 de setembro de 1990. Dispõe sobre as condições para a promoção, proteção e recuperação da saúde, a organização e o funcionamento dos serviços correspondentes e dá outras providências. Diário Oficial da União, Brasília, DF, 19 set. 1990. Disponível em: < http://www.planalto.gov.br/ccivil_03/leis//8080.htm>. Acesso em: 06 set. 2021.

BRASIL. Lei no 11.129, de 30 de junho de 2005. Institui o Programa Nacional de Inclusão de Jovens; cria o Conselho Nacional da Juventude - CNJ e a Secretaria Nacional de Juventude; altera as Leis $n^{\circ} \mathrm{s}$ 10.683, de 28 de maio de 2003, e 10.429, de 24 de abril de 2002; e dá outras providências. Diário Oficial da União, 01 de jul. de 2005. Disponível em: <http://www.planalto.gov.br/ccivil_03/_ato20042006/2005/lei//11129.htm>. Acesso em: 06 set. 2021.

BRASIL. Portaria no 336, de 19 de fevereiro de 2002. Estabelecer que os Centros de Atenção Psicossocial poderão constituir-se nas seguintes modalidades de serviços: CAPS I, CAPS II e CAPS III, definidos por ordem crescente de porte/complexidade e abrangência populacional. Ministério da Saúde, fev. 2002. Disponível em: < https://bvsms.saude.gov.br/bvs/saudelegis/gm/2002/prt0336_19_02_2002.html>. Acesso em: 06 set. 2021.

CAMARGO, T. V. Atuação da farmacêutica em centro de atenção psicossocial: Adulto (CAPS). Revista Científica Multidisciplinar Núcleo do Conhecimento, ano 1, v.7, p. 16-23, 2016.

CONSENSO BRASILEIRO DE ATENÇÃO FARMACÊUTICA. Brasília: Organização Pan-Americana da Saúde, 2002. 24 p. Disponível em: $<$ https://bvsms.saude.gov.br/bvs/publicacoes/PropostaConsensoAtenfar.pdf>. Acesso em: 07 set. 2021. 
FERNANDES, F. D. M. Terapia de linguagem em crianças com transtornos do espectro autístico. Tratado de Fonoaudiologia. São Paulo: Roca, 2004.

MARTINS, A. D. F.; GÓES, M. C. R. Um estudo sobre o brincar de crianças autistas na perspectiva histórico-cultural. Revista Semestral da Associação Brasileira de Psicologia Escolar e Educacional, v. 17, n. 1, p. 25-34, 2013.

NIKOLOV, R.; JONKER, J.; SCAHILL, L. Autismo: tratamentos psicofarmacológicos e áreas de interesse para desenvolvimentos futuros. Revista Brasileira de Psiquiatria, v. 38, s. I, p. 39-46, 2006.

OLIVEIRA, F. C. A. et al. Perfil farmacoterapêutico de crianças autistas de uma clínica para reabilitação no estado do Ceará. Boletim Informativo Geum, v. 6, n. 3, p. 43-49, 2015.

ORGANIZAÇÃO MUNDIAL DA SAÚDE (OMS). OMS pede aumento maciço nos investimentos em saúde mental. Nações Unidas no Brasil, 2020. Disponível em: $<$ https://brasil.un.org/pt-br/88989-oms-pede-aumento-macico-nos-investimentos-emsaude-mental>. Acesso em: 07 set. 2021.

SCARCELA, A. M. A.; MUNIZ, J. W. A.; CIRQUEIRA, J. Z. Investigação do uso indiscriminado de amoxicilina em crianças na faixa etária de 2 a 10 anos. Cenarium Pharmacêutico, n. 4, 2011.

SILVA, C. A.; ARAUJO, M. D. Programa de Residência Multiprofissional em Saúde: o que mostram as publicações. Saúde Debate, v. 43, n. 123, p. 1240-1258, 2019.

SUNAKOZAWA, V. R.; MATHIAS, L. I. S.; VIDOTTI, M. Z. Autismo: importância do diagnóstico precoce. Revista Científica Multidisciplinar Núcleo do Conhecimento, v. 02, n. 9, p. 05-11, 2020. 